\title{
The relationship between quality of life after childbirth and the childbirth method in nulliparous women referred to healthcare centers in Sanandaj, Iran
}

\author{
Farzaneh Zaheri ${ }^{1}$, Lila Hashemi Nasab ${ }^{2}$, Fariba Ranaei ${ }^{2}$, Roonak Shahoei ${ }^{3,4}$
}

${ }^{1}$ Ph.D. Student, Lecturer, Department of Midwifery, Faculty of Nursing \& Midwifery, Kurdistan University of Medical Sciences, Sanandaj, Iran

${ }^{2}$ M.Sc. of Midwifery, Faculty Member, Department of Midwifery, Faculty of Nursing \& Midwifery, Kurdistan University of Medical Sciences, Sanandaj, Iran

${ }^{3}$ Ph.D. of Midwifery, Associate Professor, Clinical Care Research Center, Kurdistan University of Medical Sciences, Sanandaj, Iran

${ }^{4}$ Department of Midwifery, Faculty of Nursing \& Midwifery, Kurdistan University of Medical Sciences, Sanandaj, Iran

\section{Type of article: Original}

\begin{abstract}
Background and aim: Postpartum period is associated with significant changes in the quality of women's lives. These changes can affect the health of both the mother and child. Given the importance of the postpartum period and the factors influencing quality of life after childbirth especially the method of childbirth, the aim of this study was to determine the relationship between quality of life after childbirth and the childbirth method in nulliparous women referred to healthcare centers in Sanandaj, Iran.

Methods: In this cross-sectional study, ten healthcare centers in Sanandaj, Iran from 2014-to 2015 were chosen using a cluster random sampling method. The samples consisted of 410 nulliparous women. The Edinburgh postnatal depression scale was used for data collection in the third trimester of pregnancy. Those women with a score greater than 12 were excluded from this study. The quality of life in physical, psychological, social, environmental domains and the overall quality of life were measured and compared using the World Health Organization quality of life brief questionnaire. Data were analyzed using SPSS version 22. We used descriptive statistics, Chi-square, and t-test for the analyses of outcomes.

Results: The means of quality of life in the groups of vaginal and cesarean childbirth were $98.29 \pm 11.82$ and $100.4 \pm 10.26$, respectively, which had no statistically significant differences.

Conclusion: Women with vaginal childbirth had the slightly higher quality of life scores than cesarean during 6 weeks after birth and later. Thus, providing more information to pregnant women to encourage them to use vaginal childbirth is suggested.

Keywords: Quality of Life, Vaginal Childbirth, Caesarean, Pregnancy
\end{abstract}

\section{Introduction}

Nowadays, increasing longevity and the life expectancy index have attracted attention to the concept of quality of life (1). Quality of life is a complex and subjective concept (2). The World Health Organization (WHO) defines quality of life as the perception of individuals of their lives and value systems and cultural context in which they live and in relation to their goals, expectations, relationships, needs and attitudes $(3,4)$. The quality of life is a sense of well-being stemmed from satisfaction or dissatisfaction with the various aspects of life that are important to the person. It includes the areas of health and work, socio-economic, emotional, psychological and familial. The measurement of the quality of life and consideration of living conditions, social and environmental factors, attitudes, interests, goals and values of society play an important role in efforts for health promotion planning. It can also be

\section{Corresponding author:}

Associate Professor Dr. Roonak Shahoei, Clinical Care Research Center, Kurdistan University of Medical Sciences, Sanandaj, Iran. Tel: +98.9183712759, Email: rshaho@yahoo@com

Received: March 31, 2017, Accepted: August 18, 2017, Published: December 2017

iThenticate screening: August 16, 2017, English editing: November 07, 2017, Quality control: November 15, 2017

This article has been reviewed / commented by four experts

(C) 2017 The Authors. This is an open access article under the terms of the Creative Commons Attribution-NonCommercialNoDerivs License, which permits use and distribution in any medium, provided the original work is properly cited, the use is non-commercial and no modifications or adaptations are made. 
measured in pregnancy, childbirth and after childbirth (5). Quality of life at all stages of life, including during pregnancy and after childbirth can be evaluated (6). Many changes in physical health, psychological, social and overall quality of life occur during pregnancy and postpartum in women (7). Currently, the improvement of the quality of life is the center of attention by people and governments and its measurement is very crucial for health promotion planning (8). The postpartum period is associated with significant changes in the quality of women's lives. These changes can affect the health of both the mother and the child. This period is a time of transition for the mother and her family members and needs adaptation in the aspects of physical, psychological and social (9). Women in the postpartum period encounter many physical and mental challenges so that 86 percent of them suffer from physical problems and 10-20 percent experience postpartum depression during the first two months after childbirth (10). One of the factors affecting the health and quality of life at this period is the method of childbirth (11). Mothers, after vaginal childbirth, may experience fatigue, lethargy, sleep problems, breast pain, physical pain, hemorrhoids, constipation, sexual dysfunction and postpartum depression. Following cesarean childbirth, a patient may experience increased length of hospital stay, obstetric complications such as infection, hemorrhage, thrombosis, pelvic injuries, cesarean wound and breathing problems in newborns. The mothers' experiences of postpartum problems affect their physical and mental health, quality of life and the health of their child (12-15). Huang et al., in China, conducted a study during a 12-month period after childbirth on women living in 30 settlements (15). They found that the childbirth method had no statistically significant impact on the quality of life after childbirth. A probable reason for such a result is the socio-cultural variables influencing the experience of childbirth (15). A study by Janson et al. on 141 mothers with vaginal childbirth ( 71 subjects), elective cesarean childbirth ( 36 subjects) and emergency cesarean childbirth $(n=34)$ showed that the total mean score for quality of life six weeks after childbirth was significantly higher than caesarean childbirth (7). In a study by Abedian et al. (3) on women in the vaginal and cesarean childbirth groups immediately after childbirth and two weeks after childbirth, the scores of the quality of life in the domain of physical health were significantly higher in the vaginal childbirth group compared with the cesarean childbirth group. Also, during this period, in the domain of mental health, the quality of life in the vaginal childbirth group was significantly higher than the cesarean childbirth group. However, no differences were found between the groups in terms of social, environmental domains and the overall quality of life score (3). While a Symon et al. (2003) study showed that the age and method of childbirth had no effect on their quality of life (6). Based on a proposal by the World Health Organization, incidence of cesarean section should not exceed $15 \%$ of total deliveries (16). Based on the results of different studies, the rates of caesarean are very high in Iran (17-20) and according to the statistics, this rate was reportedly $26 \%$ up to $60 \%$ in comparison with a private institute which was reported up to $87 \%$ (2). A study by Zandvakili et al. showed that cesarean section delivery rate in Sanandaj was $42.18 \%$ in 2012-2013 which is higher than cesarean section recommended by the WHO (21). The improvement of the mothers' quality of life in the postpartum period guarantees and improves the quality of life among children, families and society (22). In addition, there are limited studies on the relationship between the method of childbirth and the postpartum quality of life in Iran; therefore, this study aimed to determine the relationship between the quality of life after childbirth and the childbirth method in nulliparous women referred to healthcare centers in Sanandaj, Iran.

\section{Material and Methods}

The population of this cross sectional study was all nulliparous women referred to healthcare centers in Sanandaj, Iran. The sample size was determined as 410 people. The cluster random sampling method was used to recruit the samples. Two healthcare centers were randomly selected from the north, south, east, west and central areas of Sanandaj city. All women who had inclusion criteria and agreed to participate entered into the study. The Edinburgh depression scale was used on all volunteers in the third trimester to determine the depression score and select nulliparous women. Women who had a score of less than 12 from the Edinburgh postnatal depression scale were chosen. Inclusion criteria were being Iranian, first pregnancy, receiving prenatal care and score of less than 12 from the Edinburgh postnatal depression scale. Exclusion criteria included known physical or mental illness in the mother, a history of diabetes during pregnancy, stillbirth, deformities in the child, infant hospitalization in the hospital, feeding the child by formula, the childbirth weight of less than 2500 gr, premature birth and separation from the husband. Data were collected using a questionnaire through holding interviews with the samples. This questionnaire included two parts: socio-demographic and labor profile in the postpartum period. The validity and reliability of the Edinburgh depression scale was confirmed by the study by Montazeri et al. (23). The validity and reliability of the questionnaire were assessed by the authors. Questionnaire validity was confirmed by content validity and its reliability was evaluated by test-retest method $(\mathrm{r}=0.82)$. Next, those mothers who had depression scores of less than 12 were enrolled. The World Health Organization quality of life-brief questionnaire (WHOQLBREF) in the third trimester of pregnancy as well as after childbirth (the second and eighth weeks and six months 
after childbirth) were filled out by the samples. The WHOQL-BREF consisted of four domains: physical health, mental health, social relationships and environment health with 26 questions. Each of the above-mentioned domains consisted of seven, six, three, and eight questions, respectively. The first two questions did not belong to any of the domains and only measured the general health status and overall quality of life. A five-point Likert scale was used for scoring with 0 and 100 indicating the least and highest scores, respectively. It is noted that a high score meant a better quality of life condition (3). The validity and reliability of this questionnaire was determined by Karimloo et al. (24). The validity and reliability of the questionnaire were assessed by the authors. Questionnaire validity was confirmed by content validity and its reliability was evaluated by test-retest method $(r=0.74)$. The data were analyzed using SPSS version 22. We used descriptive statistics, Chi-square, and t-test for the analyses of outcomes. Participants filled the questioners two and six weeks after childbirth when they referred to health care centers and 6 months after delivery.

\section{Results}

In this study, 410 women including 275 women with vaginal childbirth and 135 women with cesarean childbirth participated. The mean age of the women in vaginal childbirth and the cesarean childbirth groups were $25.14 \pm 429$ years and 26.96 \pm 4.89 years, respectively. The mean of newborn weight in the vaginal childbirth group was $3203 \pm 3.84$ gr and in the cesarean childbirth group was $3275 \pm 457.67 \mathrm{gr}$. The maternal body mass index (BMI) in the above-mentioned groups were $24.63 \pm 3.84$ and $25.32 \pm 3.95$, respectively. No statistically significant differences were found in some socio-demographic characteristics of the samples. The only exception was in the relationships between age $(p=0.000)$, educational level $(p=0.004)$, occupation $(p=0.000)$, and the place of childbirth $(p=0.000)$ and quality of life (Table 1).

Table 1. Samples' demographic and obstetric characteristics $(\mathrm{n}=410)$

\begin{tabular}{|c|c|c|c|c|c|c|}
\hline \multirow{2}{*}{\multicolumn{2}{|c|}{ Characteristics }} & \multicolumn{2}{|c|}{ Vaginal childbirth } & \multicolumn{2}{|c|}{ Cesarean childbirth } & \multirow[t]{2}{*}{ p-value } \\
\hline & & $\mathrm{n}$ & $\%$ & $\mathrm{n}$ & $\%$ & \\
\hline \multirow[t]{4}{*}{ Age (Years) } & $\leq 20$ & 23 & 8.36 & 12 & 8.89 & \\
\hline & $21-30$ & 175 & 63.64 & 57 & 42.22 & \\
\hline & $31-40$ & 49 & 17.82 & 49 & 36.30 & \\
\hline & $\geq 40$ & 28 & 10.18 & 17 & 12.59 & \\
\hline \multirow[t]{4}{*}{ Education } & Illiterate & 41 & 14.9 & 15 & 11.1 & \\
\hline & Primary & 53 & 19.3 & 13 & 9.6 & \\
\hline & Secondary & 120 & 43.6 & 56 & 41.5 & \\
\hline & University & 61 & 22.2 & 51 & 37.8 & \\
\hline \multirow[t]{2}{*}{ Occupation } & Home Attendant & 24 & 8.7 & 38 & 28.1 & \\
\hline & Employed & 251 & 91.3 & 97 & 71.9 & \\
\hline \multirow[t]{2}{*}{ Residence } & Urban & 258 & 93.8 & 130 & 96.3 & \\
\hline & Rural & 17 & 6.2 & 4 & 3.0 & \\
\hline \multirow[t]{2}{*}{ Type of pregnancy } & Wanted & 246 & 89.5 & 122 & 90.4 & \\
\hline & Unwanted & 29 & 10.5 & 1 & 9.6 & \\
\hline \multirow[t]{2}{*}{ Child sex } & Male & 130 & 47.3 & 77 & 57.1 & \\
\hline & Female & 145 & 52.7 & 58 & 42.9 & \\
\hline \multirow[t]{3}{*}{ Place of birth } & Public hospital & 188 & 68.4 & 93 & 68.9 & \\
\hline & Private hospital & 8 & 2.9 & 18 & 13.3 & \\
\hline & Social security hospital & 79 & 28.7 & 24 & 17.8 & \\
\hline \multirow[t]{3}{*}{ Satisfaction of Marital relations } & Very satisfaction & 128 & 46.5 & 62 & 46.7 & \\
\hline & Satisfaction & 146 & 53.1 & 70 & 51.9 & \\
\hline & Dissatisfaction & 1 & 0.4 & 2 & 1.5 & \\
\hline \multirow[t]{3}{*}{ Satisfaction of spouse support } & Very satisfaction & 147 & 53.5 & 67 & 46.6 & \\
\hline & Satisfaction & 126 & 45.8 & 63 & 46.7 & \\
\hline & Dissatisfaction & 2 & 0.7 & 5 & 3.7 & \\
\hline \multirow{3}{*}{$\begin{array}{l}\text { Satisfaction of spouse family } \\
\text { during pregnancy }\end{array}$} & Very satisfaction & 108 & 39.3 & 45 & 33.3 & \\
\hline & Satisfaction & 145 & 52.7 & 78 & 57.8 & \\
\hline & Dissatisfaction & 22 & 8.0 & 12 & 8.9 & \\
\hline
\end{tabular}

The means of quality of life in the groups of vaginal and cesarean childbirth were $98.29 \pm 11.82$ and $100.4 \pm 10.26$ respectively during pregnancy which had no statistically significant differences $(\mathrm{p}=0.12)$. The scores of the quality of life's domains in the cesarean childbirth group during pregnancy were higher than in the vaginal childbirth group, which had no statistically significant differences (Table 2). The total scores of quality of life two weeks and six weeks after childbirth in the women with vaginal childbirth and women with cesarean childbirth were $96.58 \pm 13.64$, 
$100.53 \pm 13.84$ and $97.86 \pm 13.81,100.18 \pm 12.81$ respectively $(\mathrm{p}=0.73)$. Also, the total quality of life six months after child birth vaginal childbirth and cesarean women were $101.34 \pm 13.99$ and $103.29 \pm 14.28$ respectively $(\mathrm{p}=0.43)$. The quality of life's scores in the women with cesarean childbirth two weeks after childbirth in all domains were higher than the women with vaginal childbirth. While six weeks after childbirth the scores of quality of life in the mental, social and environment health domains were higher in the vaginal childbirth group compared with the cesarean childbirth group. The scores of all domains of quality of life six months after childbirth were higher in the cesarean childbirth group compared with the vaginal childbirth group (Table 2).

Table 2. Participants' quality of life during different periods

\begin{tabular}{|c|c|c|c|c|}
\hline Time & Qol dimension & Vaginal Delivery (mean/SD) & Cesarean Delivery (mean/SD) & p-value \\
\hline \multirow[t]{4}{*}{ During pregnancy } & Physical & $26.17 \pm 3.82$ & $3.66 \pm 26.46$ & 0.51 \\
\hline & Emotional & $22.30 \pm 3.18$ & $3.04 \pm 22.93$ & 0.27 \\
\hline & Social & $11.94 \pm 1.86$ & $1.62 \pm 11.95$ & 0.13 \\
\hline & Environmental & $29.79 \pm 4.39$ & $4.19 \pm 30.51$ & 0.89 \\
\hline \multirow{4}{*}{$\begin{array}{l}2 \text { weeks after } \\
\text { delivery }\end{array}$} & Physical & $4.33 \pm 25.50$ & $4.29 \pm 25.88$ & 0.97 \\
\hline & Emotional & $3.79 \pm 21.88$ & $3.81 \pm 22.24$ & 0.96 \\
\hline & Social & $2.05 \pm 11.62$ & $1.93 \pm 11.72$ & 0.19 \\
\hline & Environmental & $4.65 \pm 29.54$ & $4.87 \pm 30.14$ & 0.75 \\
\hline \multirow{4}{*}{$\begin{array}{l}6 \text { weeks after } \\
\text { delivery }\end{array}$} & Physical & $27.16 \pm 3.79$ & $27.30 \pm 3.74$ & 0.97 \\
\hline & Emotional & $23.03 \pm 3.68$ & $22.83 \pm 3.69$ & 0.43 \\
\hline & Social & $12.22 \pm 4.53$ & $11.83 \pm 2.05$ & 0.45 \\
\hline & Environmental & $30.13 \pm 5.13$ & $30.11 \pm 4.89$ & 0.99 \\
\hline \multirow{4}{*}{$\begin{array}{l}6 \text { months after } \\
\text { delivery }\end{array}$} & Physical & $27.77 \pm 3.73$ & $28.66 \pm 6.26$ & 0.29 \\
\hline & Emotional & $23.18 \pm 3.83$ & $23.22 \pm 3.57$ & 0.43 \\
\hline & Social & $11.80 \pm 2.17$ & $12.02 \pm 2.02$ & 0.48 \\
\hline & Environmental & $30.45 \pm 5.53$ & $30.92 \pm 4.92$ & 0.07 \\
\hline
\end{tabular}

\section{Discussion}

The results of this study showed that the quality of life during pregnancy in the two groups had no significant difference. Our findings are consistent with those of the study by Mousavi et al. (25). They compared the quality of life of 345 women after cesarean and vaginal childbirth and used the WHOQOL- BREF for data collection in the third trimester of pregnancy. The researchers reported that no statistically significant differences were observed between the groups (25). We found that the quality of life two weeks after childbirth was slightly higher in the cesarean childbirth group than the vaginal childbirth group. Although this difference was not statistically significant, it can be attributed to further support by the family, because of the mother's inability to perform daily activities $(\mathrm{p}=0.73)$. Also, the quality of life scores two weeks after childbirth were higher in the cesarean childbirth group, though the differences were not statistically significant. These results are in line with those of the study by Huang et al. (15). However, these results did not match with the findings of Abedian et al. indicating that the score of the physical domain of quality of life two weeks after childbirth was higher in the caesarean childbirth group (3). Also, Mousavi et al. showed that all domains of quality of life after childbirth in the vaginal childbirth group were higher than in the caesarean childbirth group (25). The studies by Kavoosi et al. and Alshehir et al. showed that the scores of the quality of life's domains after childbirth in the vaginal childbirth group was higher than in the cesarean childbirth group $(26,27)$. This difference in result may be due to our medical institutionalization and intervention during vaginal childbirth in our center. There are some interventions during vaginal childbirth such as using oxytocin for labor augmentation, vaginal examination, fundal pressure, episiotomy that effect women's feelings and quality of life during postpartum. We found that in the vaginal childbirth group, the total score of quality of life six weeks after childbirth was greater than the cesarean childbirth group, but the difference was not statistically significant. In the study of Jansen et al. (2007), no such a difference was reported between the vaginal childbirth and cesarean childbirth groups (7). Such a result may be attributed to the positive effects of labor and childbirth experiences on mothers that make them feel empowered for the motherhood role (23). Also, women who go through natural childbirth are extremely empowered and feel much more confident and this could make a woman feel stronger and less fearful about handling other challenges in life. Mothers who deliver vaginally are able to breastfeed immediately and more effectively than women with cesarean childbirth. Furthermore, the recovery period after cesarean childbirth is longer than vaginal childbirth because of more pain and discomfort in the abdomen as the skin and nerves surrounding the surgical scar need time to heal. Caesarean section is not simply a mode of childbirth, it is also an operation, and like any form of surgery, particularly emergency surgery, can cause health problems. Caesarean delivery increases the incidence of surgical intervention and problems resulting from 
hospitalization. It also puts financial pressure on family and society. A study comparing early postpartum sleep and fatigue for mothers after caesarean section and vaginal delivery found that mothers with vaginal delivery had less hospitalization and more total sleep time (28). In this study, we also found that overall, women with vaginal childbirth reported a quality of life score slightly higher than cesarean childbirth. According to our findings, the score of social domain of quality of life six weeks after childbirth was greater in the vaginal childbirth group than the caesarean childbirth group, but the difference was not statistically significant. Our findings are in line with the findings of Sadat et al., Alshehri et al., and Nikpour et al. (22, 27, 29). Social support plays an important role in reducing stress in mothers in the postpartum period and affects their experiences of childbirth (24). Many studies have shown that mothers' adaptive behaviors have relationships with their understandings and perceptions. In this respect, appropriate marital relationships and relationships with friends and relatives affect their motherhood role (25). Our findings are different from the findings in the study of Majzoobi et al.(30). In a study with the aim of comparing quality of life after vaginal and caesarean childbirth, they studied 2,100 women referred to healthcare centers in Hamedan, Iran. They used the WHO-BREF to evaluate the quality of life one week, two months, four months, six months and one year after childbirth. They reported that the quality of life in the women with vaginal childbirth was greater than the women with caesarean childbirth (30). In this study, the WHO-BREF was used. Since the quality of life is a self-reported and subjective concept, the accuracy of the answers given by the women cannot be verified, which can be considered a limitation of this study. Also in the cesarean childbirth group, the cause for cesarean childbirth as elective or emergency which could influence the women's quality of life, was not investigated in this study. It is suggested to study the factors influencing the quality of life after childbirth with a larger sample size in future studies.

\section{Conclusions}

Women with vaginal childbirth had the slightly higher quality of life scores than cesarean during 6 weeks after birth and later. Thus, providing more information to pregnant women to encourage them to use vaginal childbirth is suggested.

\section{Acknowledgments:}

The study resulted from a research which was approved by the Ethics Committee of Kurdistan University of Medical Sciences and was conducted with financial help of Kurdistan University of Medical Sciences. Therefore, the authors would like to thank the deputy dean of research in the faculty of nursing and midwifery, the deputy dean of research and the ethics committee affiliated with this university. Also, the authors wish to thank all midwives and participants who made this study.

\section{Conflict of Interest:}

There is no conflict of interest to be declared.

\section{Authors' contributions:}

All authors contributed to this project and article equally. All authors read and approved the final manuscript.

\section{References:}

1) Ahmadi F, Salar A, Faghihzadeh S. Quality of life in Zahedan elderly population. Hayat. 2004; 10(3): 61-7.

2) Nagpal J, Dhar RS, Sinha S, Bhargava V, Sachdeva A, Bhartia A. An exploratory study to evaluate the utility of an adapted mother generated index (MGI) in assessment of postpartum quality of life in india. Health Qual Life Outcomes. 2008; 6(107): 1-10. doi: 10.1186/1477-7525-6-107. PMID: 19055710, PMCID: PMC2651123.

3) Abedian Z, Nikpour M, Mokhber N, Ibrahimzade S, Khani S. The relationship between type of delivery and postpartum quality of life. Journal of Obstetrics, Gynecology and Infertility. 2010; 13(3): 53-47.

4) Bahrami N, Bahrami S. The survey of quality of life in first-time women in postpartum period. IJNR. 2012; 6(23): 59-64.

5) Karami K, Bakhtiar K, Hasanvand B, Safary S, Hasanvand S. A comparison of life quality and public health after natural and cesarean delivery in women referred to khorramabad health centers in 2009-2011. Yafteh. 2012; 14(4): 59-69.

6) Symon A, Mackay A, Ruta D. Postnatal quality of life: a pilot study using the mother-generated index. J Adv Nurs. 2003; 42(1): 21-9. doi: 10.1046/j.1365-2648.2003.02575.x.

7) Jansen AJ, Duvekot JJ, Hop WC, Essink-Bot ML, Beckers EA, Karsdorp VH, et al. New insights into fatigue and health-related quality of life after delivery. Acta Obstet Gynecol Scand. 2007; 86(5): 579-84. doi: $10.1080 / 00016340701275424$. 
8) Aga molai T, Eftekhar Ardbili H. Principle of health services. 1st ed. Tehran: Andish Rafie Publishing; 2005: 66-77.

9) Shaw E, Levitt C, Wong S, Kaczorowski J. Systematic review of the literature on postpartum care: effectiveness of postpartum support to improve maternal parenting, maternal health, quality of life, and physical health. Birth. 2006; 33(3): 210-20. doi: 10.1111/j.1523-536X.2006.00106.x. PMID: 16948721.

10) Mckee MD, Cunningham M, Jankowski KR, Zayas L. Health related functional status in pregnancy: relationship to depression and social support in a multi- ethnic population. Obstet Gynecol. 2001; 97(6): 987-93. doi: 10.1097/00006250-200106000-00022. PMID: 11384708.

11) Khakbazan Z, Golyan Tehrani Sh, Payghambardoost R, Kazemnejad A. Effect of Telephone Counseling during Post-Partum Period on Women's Quality of Life. Journal of Faculty of Nursing and Midwifery, Tehran University of Medical Sciences. 2010; 15(4): 5-12.

12) Sadat Z, Saberi F, Taebi M, Abedzadeh M. Comparison of quality of life after normal delivery and Caesar. Payesh. 2012; 11(3): 377-83.

13) Zhou SZ, Wang XL, Wang Y. Design of a questionnaire for evaluation the quality of life of postpartum women in china. Qual life Res2009:18:497-508. doi: 10.1007/s11136-009-9466-2. PMID: 19319664.

14) Bibi S, Ghaffar S, Memon S, Memon S. Severe acute maternal morbidity (SAMM) in postpartum period requiring tertiary Hospital care. Iran J Reprod Med. 2012; 10(2): 87-92. PMID: 25242979, PMCID: PMC4163268.

15) Huang K, Tao F, Liu L, Wu X. Does delivery mode affect women's postpartum quality of life in rural China? JNC. 2011: 1-10. doi: 10.1111/j.1365-2702.2011.03941.x.

16) Rezaei M, Zandvakili F, Shahoei R, Roshani D, Farhadifar F. Modes of delivery and maternal outcomes in women referred to sanandaj hospitals in 2013. Iranian Journal of Obstetrics, Gynecology and Infertility. 2016; 18(185): 1-9. doi: 10.22038/ijogi.2016.6746.

17) Shahoei R, Rezaei M, Ranaei F, Khosravy F, Zaheri F. Kurdish women's preference for mode of birth: a qualitative study. IJNP. 2014; 20: 302-9. doi: 10.1111/ijn.12150.

18) Torkzahrani S. Commentary: childbirth education in Iran. J Perinat Educ. 2008; 17(3): 51-4. doi: 10.1624/105812408X329601. PMID: 19436412, PMCID: PMC2517184.

19) Shareferad G, Fathean Z, Terane M, Mahake B. The Survey of pregnant women views about delivery and cesarian According Behavioral intention model. Elam Uni Med Sci J. 2007; 15(1): 20-3.

20) Bani S, Seyed Rasouli A, Shams Ghorashi T, Ghojazadeh M, Hassan pour S. Delivery Agents Preferences Regarding Mode of Delivery for Themselves and Pregnant Women (Obstetrics, Gynecologists, Midwives). J of Nurs and Midwi. 2010; 18(5): 40-8.

21) Zandvakili F, Rezaie M, Shahoei R, Roshani D. Maternal outcomes associated with cesarean versus vaginal delivery. JCDR. 2017; 11(7): 1-4. doi: 10.7860/JCDR/2017/24891.10239.

22) Sadat Z, Saberi F, Taebi M, Abedzadeh M. Relationship between women's quality of life and type of delivery. J Gorgan Uni Med Sci. 2011; 13(1): 101-8.

23) Montazeri A, Torkan B, Omidvari S. The Edinburgh Postnatal Depression Scale (EPDS): translation and validation study of the Iranian version. BMC Psychiatry. 2007; 7(11): 1-6.

24) Karimlou M, Salehi M, Zayeri F, Massah Choolabi O, Hatami A, Moosavy Khattat M. Developing the Persian Version of the World Health Organization Quality of Life-100 Questionnaire. Rehabilitation. 2011; 11(4): 73-82.

25) Mousavi SA, Mortazavi F, Chaman R, Khosravi A. Quality of life after cesarean and vaginal delivery. Oman Medical Journal. 2013; 28(4): 245-51. doi: 10.5001/omj.2013.70.

26) Kavosi Z, Keshtkaran A, Setoodehzadeh F, Kasraeian M, Khammaria M, Eslahi M. A comparison of mother's quality of life after normal vaginal, cesarean, and water birth deliveries. IJCBNM. 2015; 3(3): 198-204. PMID: 26171408 , PMCID: PMC4495327.

27) Alshehri NM, Alanazi AQ, Alanazi MQ, Alanazi WQ, Alanazi JQ, Alenazi BQ, et al. Relationship between health related quality of life determinants and type of delivery in Saudi women. Fam Med Med Sci Res. 2015; 4(1): 1-4. doi: 10.4172/2327-4972.1000155.

28) Lee SY, Lee KA. Early postpartum sleep and fatigue for mothers after caesarean delivery compared with vaginal delivery: an exploratory study. J Perinat Neonatal Nurs. 2007; 21: 109-13. doi: 10.1097/01.JPN.0000270627.73993.b0. PMID: 17505230.

29) Nikpour M, Abedian Z, Mokhber N, Ebrahimzadeh S, Khani S. Comparison of quality of life in women after vaginal delivery and cesarean section. J Babol Univ Med Sci. 2011; 13(1): 44-50.

30) Majzoobi MM, Majzoobi MR, Nazari P, Biglari M, Poorolajal J. Comparing quality of life in women after vaginal delivery and cesarean section. JMRH. 2014; 2(4): 207-14. 